\section{Uma Possibilidade de Autoria em}

\section{Textos Dissertativo-Argumentativos:}

Propostas de Atividades

A Possibility to Enhance Authorship in Argumentative Essays: Suggestions of Exercises

Laila Rayssa de Oliveira Costa*, Sâmia Araújo dos Santos

RESUMO: Este trabalho tem como objetivo propor atividades que contribuam para o desenvolvimento da autoria segundo o que espera o material Redação no Enem 2018 - Cartilha do Participante presente no site do Inep (INEP, 2018). Para isso, tratamos do conceito de autoria de modo mais amplo, para Barthes (2012), Foucault (2009) e Bakhtin (2010), e também mais específico, isto é, do âmbito escolar, dialogando com Possenti $(2002$; 2013) e Orlandi (1988). Partimos então da Análise do Discurso, mas também bebemos na Linguística de Texto, principalmente, com Cavalcante (2017) ao discutirmos coerência. Após refletirmos acerca do conceito de autoria e de coerência, produzimos atividades com o objetivo de contribuir para o trabalho do professor de ensino médio de língua materna quando este for trabalhar autoria, projeto de texto e coerência em suas aulas de produção de texto com os seus alunos.

PALAVRAS-CHAVE: Autoria; Projeto de texto; Ensino; Enem.

ABSTRACT: This work aims to propose activities that contribute to the development of authorship according to what is expected in the composition instructions of Enem (National High School Exam) from 2018. These instructions are written in the Student Booklet, available on the National Institute of Educational Studies and Research Anísio Teixeira website (INEP, 2018). As a theoretical scope, we worked with the concept of authorship based on Discourse Analysis, using the studies of Barthes (2012), Foucault (2009) and Bakhtin (2010). In addition, we looked for a more specific approach, focusing on the school environment, using the ideas of Possenti (2002; 2013) and Orlandi (1988). Also, in the field of Text Linguistics, we used Cavalcante (2017) and his view on coherence. After reflecting on the concept of authorship and coherence, we produced activities with the objective of contributing to the work of high school portuguese teachers. These activities involve working into the classroom with authorship, text drafts and consistency.

KEYWORDS: Authorship; Text draft; Teaching; Enem.

\section{Linguagęm Foco \\ Revista do Programa de Pós-Graduação em Linguística Aplicada da UECE}

Mestre em Letras (UFC), Especialista em Ensino de Língua Portuguesa (UECE), professora da rede privada.

Doutora em Linguística Aplicada (UECE), Professora da Especialização Ensino de Língua Portuguesa (UECE), professora da rede privada e pública estadual de ensino do Ceará.

Distribuído sobre

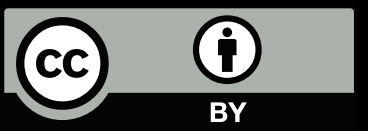




\section{INTRODUÇÃO}

A experiência na área de ensino e correção de redação nos estimulou a refletir com mais atenção sobre os textos produzidos no contexto escolar e o modo como eles são avaliadas no Exame Nacional do Ensino Médio (Enem). Embora saibamos que o papel da escola não é apenas preparar seus alunos para um vestibular, as provas de seleções, como o Enem, influenciam bastante o trabalho dos professores de redação, principalmente, quando escolas competem em busca de grandes resultados. Desses questionamentos, foi produzida a monografia que possibilitou o recorte para este artigo.

O material Redação no Enem 2018 - Cartilha do Participante (doravante cartilha do participante) é o nosso objeto de estudo já que é nele que encontramos as orientações mais detalhadas da Matriz de Referência - documento que explicita os critérios usados para a avaliação da redação - e também é o nosso ponto de partida para a análise de como é exigida a configuração da autoria para o alcance da nota máxima, a nota mil. Pela Matriz, confere-se que a avaliação da autoria se dá na competência 3 cujo objetivo é: "selecionar, relacionar, organizar e interpretar informaçóes, fatos, opiniôes e argumentos em defesa de um ponto de vista" ${ }^{1}$ Entende-se, portanto, que o candidato só alcança a nota máxima se apresentar seus argumentos em defesa de um ponto de vista, o que configuraria autoria.

Nosso objetivo geral, nesta pesquisa, é propor atividades que possibilitem a construção dessa autoria, mas, para isso, objetivos específicos precisam ser alcançados, dentre eles: compreender conceitos clássicos de autoria e a relação deles com a autoria esperada em textos de estudantes do ensino médio. Para isso, é importante analisarmos como a autoria aparece na cartilha do participante e quais os critérios estabelecidos para a excelência na competência 3 da matriz de referência das redaçóes do Enem.

O presente artigo apresenta três seçóes. A primeira discute o conceito de autoria segundo Barthes (2012), Foucault (2009) e Bakhtin (2010), inicialmente em um nível mais amplo, para depois restringir a fim de relacionar ao universo escolar. Para isso, foi usada a análise da autoria no contexto escolar a partir das consideraçóes de Possenti $(2002,2013)$ e Orlandi (1988). A segunda seção ${ }^{2}$ de como é desenvolvida a competência 3 em Redação no Enem 2018 - Cartilha do Participante, material em que são expostos os critérios avaliativos e também redaçóes nota mil. Ainda nesta seção, como a autoria está vinculada à coerência, foi apresentado esse conceito conforme a visão de Cavalcante (2017).

$\mathrm{Na}$ terceira seção, foram propostas duas atividades cuja finalidade é trazer mais possibilidades de o professor de língua materna, em suas aulas de produção de texto, desenvolver com os alunos a autoria; esta relacionada à ideia de projeto de texto. Por fim, as consideraçôes finais mostram que a análise da autoria no contexto da produção escolar foi necessária para a elaboração das atividades propostas. Esperase ainda que, em outro momento, as atividades sejam aplicadas para que os objetivos das atividades sejam alcançados.

1 Na monografia, as competências avaliativas são mais detalhadamente explicitadas, o que não faremos neste trabalho devido às limitaçôes decorrentes da configuração de um artigo.

2 Doravante iremos nos referir ao material Redação no Enem 2018 - Cartilha do Participante apenas como cartilha do participante 2018 .

\begin{tabular}{c|c|c|c}
\hline Revista Linguagem em Foco & Fortaleza, CE & v. 12 n. 1 & ISSN 2674-8266 \\
\hline
\end{tabular}




\section{A QUESTÁO DA AUTORIA}

Para Foucault (2009), a contemporaneidade traz o apagamento do sujeito autor, pois o escritor distancia a sua vida do que ele escreve, apagando-se. Portanto "a marca do escritor não é mais do que a singularidade de sua ausência" (FOUCAULT, 2009, p. 269). Apesar desse "papel do morto no jogo da escrita" (FOUCAULT, 2009, p. 269), pois esse morto seria o autor apagado de seus escritos, as noçóes de escrita e de obra preservam a existência do autor. A escrita leva ao apagamento do autor, como um papel que fora escrito e em seguida apagado, e mesmo apagado ainda resguarda as marcas do apagamento. Esses resquícios do que fora escrito trariam a ideia de que há um sentido oculto (já que o autor foi apagado) que precisa ser descoberto. Assim, o crítico seria o responsável por extrair, desvendar ou até mesmo criar as significaçóes desse sentido oculto, obscuro e implícito.

Foucault mostra que

[...] um nome de autor não é simplesmente um elemento em um discurso (que pode ser sujeito ou complemento, que pode ser substituído por um pronome etc.); ele exerce um certo papel em relação ao discurso: assegura uma função classificatória; tal nome permite reagrupar um certo número de textos, delimitá-los, deles excluir alguns, opô-los a outros (FOUCAULT, 2009, p. 273).

Assim, a imagem do autor é afetada por quem o lê, pois há influências dos discursos que o atravessam em sua escrita. A partir de tal reflexão, Foucault entende que há uma função-autor que é um "mecanismo de apropriação, marcado inicialmente pela função repressora dos autores transgressores da ordem estabelecida" (CAVALHEIRO, 2008, p. 70, grifo da autora).

Foucault (2009) mostra que o autor tem uma palavra que se destaca do cotidiano, pois ela indica o modo como deve ser recebida e ainda se receberá um certo status. Assim, existe "A função-autor [...] característica do modo de existência, de circulação e de funcionamento de certos discursos no interior de uma sociedade." (FOUCAULT, 2009, p. 274).

O filósofo ainda explora uma característica da função-autor como uma atribuição que surge espontaneamente, além disso, tenta-se criar um status realista a partir da capacidade do indivíduo, como se ele tivesse um poder-criador:

[...] na verdade, o que no indivíduo é designado como autor (ou o que faz de um indivíduo um autor) é apenas a projeção, em termos sempre mais ou menos psicologizantes, do tratamento que se dá aos textos, das aproximaçóes que se operam, dos traços que se estabelecem como pertinentes, das continuidades que se admitem ou das exclusóes que se praticam (FOUCAULT, 2009, p. 276).

Dessa forma, percebe-se que, para Foucault, a função-autor não diz respeito apenas às habilidades individuais, mas é uma estrutura mais complexa que se percebe nos textos através de traços destacáveis.

Roland Barthes (2012) discorre, em "A morte do autor", sobre o desaparecimento dessa categoria a partir de um texto balzaquiano: "Na sua novela Sarrasine, falando de um castrado disfarçado em mulher, Balzac escreve esta frase: 'Era a mulher, com os seus medos súbitos, os seus caprichos sem razão, as suas perturbaçóes instintivas, as suas audácias sem causa, as suas bravatas e a sua deliciosa delicadeza de sentimentos'. " (BARTHES, 2012, p. 57). Barthes (2012) se questiona se quem enuncia essa frase era o

\begin{tabular}{c|c|c|c}
\hline Revista Linguagem em Foco & Fortaleza, CE & v. $12 \mathrm{n} .1$ & ISSN 2674-8266 \\
\hline
\end{tabular}


indivíduo Balzac, o autor Balzac, o herói do texto ou até mesmo a psicologia romântica, isto é, ele reflete sobre o que/quem de fato produz aquele discurso e conclui que é impossível sabê-lo, pois "A escritura é esse neutro, esse composto, esse oblíquo pelo qual foge o nosso sujeito, o branco-e-preto em que vem se perder toda a identidade, a começar pela do corpo que escreve." (BARTHES, 2012, p. 57).

Barthes (2012) começa falando que o autor é uma personagem moderna, produzida pela nossa sociedade, porque "na medida em que, ao sair da idade Média, com o empirismo inglês, o racionalismo francês e a fé pessoal da Reforma, ela descobriu o prestígio do indivíduo ou, como se diz mais nobremente, da 'pessoa humana'." (BARTHES, 2012, p. 58). Assim, a importância do indivíduo tem a ver com o desenvolvimento ideológico do capitalismo. Em seguida, Barthes (2012) continua sua análise descrevendo, principalmente, a relaçáo entre o autor e a literatura, apontando que: "a imagem da literatura que se pode encontrar na cultura corrente é tiranicamente centrada no autor, na sua pessoa, na sua história, nos seus gostos, nas suas paixôes [...]” (BARTHES, 2012, p. 58).

Barthes (2012), então, discute a impessoalidade no ato de escrever que não permite a manifestação de um eu autoritário. Tal modo de ver a linguagem implica em uma aceitação de que autor e obra não têm relação de antecedência, ambos acontecem no movimento de produção da linguagem. Além disso, ainda dentro dessa lógica, o autor não seria mais o "dono" daquela produção, o que, consequentemente, daria mais poder ao leitor, permitindo pensar que tanto autor quanto leitor são os escritores do texto. Tal reflexão é interessante por oferecer maior poder ao leitor já que passa a ter sua participação mais notada e ativa, possibilitando análises textuais que ultrapassem o biografismo.

Em seguida, Barthes (2012) continua seus apontamentos trazendo a linguística para a discussão mostrando que, para essa área do conhecimento, o surgimento da enunciação permite pensá-la enquanto um processo vazio (e por isso sempre novo e irrepetível) que funciona sem a necessidade dos interlocutores e que o " autor nunca é mais do que aquele que escreve, assim como 'eu' outra coisa não é senão aquele que diz 'eu'" (BARTHES, 2012, p. 60). Portanto, se para Foucault (2009) o nome do autor terá relevância para caracterizar o discurso, para Barthes (2012), essa figura se apaga no discurso e no leitor.

Segundo Padilha (2011), a noção de autoria prevista pelo Círculo de Bakhtin é bastante diferente da função-autor de Foucault, pois "se propóe e se constrói no movimento interlocutivo, na relação alteritária" (a autoria presume um autor que percebe o outro fora do seu discurso) e vai além da linguagem literária. Ela mostra que a noção de autoria ultrapassa o âmbito artístico já que:

(...) qualquer locução realmente dita em voz alta ou escrita para uma comunicaçáo inteligível (isto é, qualquer uma (exceto palavras depositadas num dicionário) é a expressão e produto da interação social de três participantes: o falante (autor), o interlocutor (leitor) e o tópico (o que ou o quem) da fala (o herói). (VOLOCHINOV, 1926, p. 5 apud PADILHA, 2011, p. 93)

Isto é, a linguagem é vista por Volochinov (2017) e pelo Círculo Bakhtiniano como uma atividade que acontece por meio da interação, mesmo a linguagem artística. Por isso é interessante repensar a autoria por Bakhtin (2010) não apenas no âmbito literário, mas também no cotidiano e principalmente no educacional.

Além disso, Bakhtin (2010) também aborda a questão da autoria relacionada à personagem em "O autor e a personagem", a partir da perspectiva de um autor-criador, de alguém que dá forma ao objeto da 
linguagem, sendo responsável pelo acabamento da personagem (CAVALHEIRO, 2008).

Outro aspecto interessante a ser destacado do pensamento de Bakhtin (2010) é o fato de ele enxergar como impossível que o indivíduo seja neutro, já que todos ocupam "uma posição singular no acontecimento único da existência” (BAKHTIN, 2003, p. 117 apud CAVALHEIRO, 2008, p. 75), mesmo quando alguém produz uma obra estética. Para Bakhtin (2010), o autor, ao escrever sobre algo, ao destacar um aspecto ou outro, ele toma uma posição e por isso não é possível a neutralidade, e é exatamente a impossibilidade da neutralidade que permite o acabamento estético por parte do autor.

Bakhtin mostra que

O autor se realiza e realiza o seu ponto de vista não só no narrador, no seu discurso e na sua linguagem (que, num grau mais ou menos elevado, são objetivos e evidenciados), mas também no objeto da narração, e também realiza o ponto de vista do narrador. (BAKHTIN, 2010, p. 118)

Podemos inferir, então, que a figura do autor se manifesta, para a literatura, na imagem do narrador, no discurso e na linguagem, isto é, é necessário o acontecimento textual a fim de dar forma ao autor.

Faraco (2014) mostra que Bakhtin (2010), em seu texto "O autor e o herói na atividade estética", diferencia o autor-pessoa - aquele que escreve, o artista - do autor-criador - uma função estético-formal que dá forma ao objeto artístico. Faraco (2014) mostra também que, quando Bakhtin (2010) escreve "O problema do conteúdo, do material e da forma na criação literária”, o teórico adiciona a sua perspectiva de autor enquanto posição axiológica, que inclui não apenas a visão de um herói, mas o modo como o objeto estético é materializado, isto é, o autor criador também é responsável pelas escolhas composicionais, já que há escolhas valorativas nesse processo.

Para Foucault (2009) a função-autor marcar um modo de existência e circulação na linguagem, para Barthes (2010) há um apagamento do autor no discurso e para Bakhtin (2010), o autor dá forma ao objeto artístico, mas também impossibilita uma neutralidade. A partir desses posicionamentos, consideramos que o autor é responsável pela estrutura linguística e pela organização das ideias que serão marcas de sua existência no texto e, sendo este uma produção relacionada a uma manifestação da opinião, o autor não poderá se manter neutro.

$\mathrm{Na}$ perspectiva escolar, isto é, produçôes textuais realizadas por estudantes, o objetivo é fazer com que eles tenham consciência de mostrar a sua opinião. Entretanto, a organização textual, neste trabalho, do aluno do ensino médio pressupóe um objeto: o Exame Nacional do Ensino Médio (ENEM).

\subsection{A AUTORIA NO CONTEXTO ESCOLAR}

Além desses teóricos que desenvolveram pensamentos em torno da questão da autoria de um modo geral, há outros que trazem esta categoria para o universo da redação escolar, como é o caso de Sírio Possenti, nos textos "Indícios de autoria" (2002) e "Notas sobre a questão da autoria" (2013).

No primeiro, Possenti (2002) diz que considerar um texto bom ou ruim tem mais relação com "como" ele é escrito do que com "o quê" é escrito, assim, ele associa essa ideia à prática escolar, a qual, durante algum tempo, prezou mais pela mensagem a ser transmitida pelo aluno, devido a uma ideologia 
educacional que focava no desenvolvimento crítico dos estudantes; como "tanto a mensagem quanto o discurso crítico eram uma questão de 'o quê’” (POSSENTI, 2002, p. 106), o foco das correçóes era estritamente formal.

Possenti (2002) estabelece limites para o que pensa sobre autoria e faz uma análise dos conceitos já existentes relacionados a essa categoria, especialmente a de Foucault. O linguista comenta que a noçáo de autor para o pensador francês depende também da noção de obra e, por isso, a perspectiva foucaultiana impossibilitaria, para Possenti, pensar a autoria na redação escolar, já que náo é possível reconhecer se determinado estudante, em textos de seleções de vestibulares, é responsável por uma obra, até porque essa questão não é o foco dessas avaliações.

Entretanto, Possenti (2002) se dispóe a modelar a perspectiva de Foucault (2009) para a redação escolar, evitando uma avaliação apenas sobre coesão e coerência - embora vejamos mais à frente que a coerência estará na mesma competência em que se avalia a autoria nas redaçóes do Enem.

Para Possenti (2002), um texto bom só poderá ser avaliado como bom em níveis discursivos, e também é a partir disso que será avaliada a construção da autoria, mas não de forma subjetiva. Possenti busca traçar indícios e não aspectos totalmente determinantes "para evitar a consideração automática de certas marcas como definidoras da presença ou da ausência de autoria. Em outras palavras, as marcas não são mais do que indícios de autoria." (POSSENTI, 2002, p. 110).

Os indícios de autoria estariam relacionados a duas atitudes mais específicas, que seriam: "dar voz a outros enunciadores e manter a distância em relaçáo ao próprio texto." (POSSENTI, 2002, p. 112113, grifo do autor). A primeira delas seria a habilidade de trazer pontos de vistas diferentes em um texto, sendo aqueles atribuídos a diferentes enunciadores; e a segunda seria deixar claro que esses discursos são de outras situaçóes e não emitem efetivamente a opinião de quem os escreve, para isso o autor pode explicar porque usa determinados termos, por exemplo.

Em "Notas sobre a questão da autoria", Possenti (2013) retoma a questão sobre autoria abordada no texto tratado anteriormente relacionando-a ao estilo e à vida escolar, relembrando que pode haver indícios de autoria em textos estudantis, o que não significa que um estudante seja autor, até porque a redação escolar só é feita de fato na escola. Assim, aspectos como estilo foram valorizados para se identificar tais traços.

Em um posicionamento aparentemente divergente ao de Possenti (2002; 2013), Orlandi (1988, p. 56) considera que "O sujeito se constitui como autor ao constituir o texto. O autor é o lugar em que se constrói a unidade do sujeito. É onde se realiza o seu projeto totalizante. ”, entendemos, então, assim como a autora, que mesmo um aluno do ensino médio pode ser considerado autor se o seu projeto se realiza na produção textual.

A autora diz ainda que "trata-se de considerar o autor como princípio de agrupamento do discurso, como unidade e origem de suas significaçóes, como foyer de sua coerência" (ORLANDI, 1988, p. 61), ele, o autor, é então uma "sala de espera" de sua coerência, um lugar de aconchego, tranquilidade e ao mesmo tempo intervenção, já que nesse foyer estão enunciados diversos, os quais o autor vai escolher dialogar.

Esse autor é marcado também pelo que a Análise do Discurso (AD) chama de efeito-sujeito que

é o efeito ideológico necessariamente inscrito na linguagem, pelo qual o sujeito tem a impressão

\begin{tabular}{c|c|c|c}
\hline Revista Linguagem em Foco & Fortaleza, CE & v. 12 n. 1 & ISSN 2674-8266 \\
\hline
\end{tabular}


$1^{\text {a) }}$ de ser a fonte de sentido do que diz (quando na verdade retoma sentidos preexistentes); e $2^{\circ}$ ) da realidade de seu pensamento, já que, para ele, o que diz só poderia ser dito do modo como diz. Em suma, o efeito-sujeito coloca o sujeito como origem de seu dizer e representa o sentido como transparente. (ORLANDI, 1988, p. 69)

Orlandi (1988) comenta essa categoria para dizer que a AD reconhece a existência desse efeitosujeito, embora evite reproduzi-lo. O efeito-sujeito tem uma importante contribuição para a discussão já que permite apreender um outro aspecto: "o da autonomia do sujeito na constituição do sentido e da sua função na construção da unidade do texto" (ORLANDI, 1988, p. 69). Assim, se o sujeito tem autonomia para construir a unidade do texto, pode-se falar em autoria na produção textual de estudantes de nível médio.

Como já abordamos, a questão da autoria sob alguns vieses, agora iremos aprofundar a temática na direção do nosso objeto, portanto na seção seguinte daremos continuidade ao assunto, porém analisando como se dá a autoria na cartilha do participante do ENEM 2018.

\section{A AUTORIA NO MATERIAL REDAÇÃO NO ENEM 2018 - CARTILHA DO PARTICIPANTE}

A questão da autoria já vem sendo analisada em diversas pesquisas de várias áreas. Algumas delas já abordam relacionando-a à redação do Enem, prova cuja pontuação máxima é de mil pontos, que é o somatório de 5 notas, chamadas competências, cada uma podendo valer $0,40,80,120,160$ ou 200 pontos. Entretanto, para este trabalho, abordaremos especificamente como a autoria aparece na competência 3 de avaliação das redaçóes. Para a redação do Enem, a autoria é um dos critérios que o candidato precisa desenvolver bem para atingir o nível máximo (200 pontos) na competência 3, como discutido na seção anterior, A autoria no contexto escolar.

O INEP (Instituto Nacional de Estudos e Pesquisas Educacionais Anísio Teixeira) lançou o material Redação no Enem 2018 - Cartilha do Participante com o objetivo de [...] "tornar o mais transparente possível a metodologia de avaliaçáo da redação, bem como o que se espera do participante em cada uma das competências avaliadas" (INEP, 2018, p. 03). Um material de extrema relevância tanto para quem irá participar do exame, quanto para nós, professores, responsáveis pela orientação dos alunos que irão precisar fazer a prova.

Na cartilha do participante, é dito que a inteligibilidade da redação dependerá de:

- Relação de sentido entre as partes do texto.

- Precisáo vocabular.

- Seleção de argumentos.

- Progressão temática adequada ao desenvolvimento do tema, revelando que a redação foi planejada e que as ideias desenvolvidas são, pouco a pouco, apresentadas, de forma organizada, em uma ordem lógica.

- Desenvolvimento dos argumentos, com a explicitação da relevância das ideias apresentadas para a defesa do ponto de vista definido (INEP, 2018, p. 18).

Nota-se nesses pontos orientaçóes acerca da organização textual desejada o que será discutido na próxima seção, Sobre a coerência. Para se atingir tal organização, o estudante deve ser capaz de

\begin{tabular}{c|c|c|c}
\hline Revista Linguagem em Foco & Fortaleza, CE & v. 12 n. 1 & ISSN 2674-8266 \\
\hline
\end{tabular}


mostrar, através da sua produção, que seus parágrafos foram planejados, permitindo assim que o corretor identifique se os argumentos estão articulados para a defesa de um ponto de vista, o que configura a adoção de um projeto de texto pensado antecipadamente.

A referida organização que se deixa transparecer no texto do candidato - a partir de uma ordem lógica e do desenvolvimento de argumentos presumidamente relevantes para a defesa de um ponto de vista - será o que dará forma ao projeto de texto do estudante:

Assim, o texto que atende às expectativas referentes à Competência 3 é aquele no qual é possível perceber a presença implícita de um projeto de texto, ou seja, aquele em que é claramente identificável a estratégia escolhida por quem está escrevendo para defender seu ponto de vista. (INEP, 2018, p. 18)

A seção da competência 3 é bastante breve em sua explicação, porém, no final dela, há um resumo indicando o que o estudante deve fazer para desenvolver o texto e alcançar uma boa nota nessa habilidade:

Resumindo: na organização do texto dissertativo-argumentativo, você deve procurar atender às seguintes exigências:

- Apresentação clara da tese e seleção dos argumentos que a sustentam.

- Encadeamento das ideias, de modo que cada parágrafo apresente informaçóes coerentes com o que foi apresentado anteriormente, sem repetiçóes ou saltos temáticos.

- Desenvolvimento dessas ideias por meio da explicitação, explicação ou exemplificação das informaçốes, fatos e opiniốes, de modo a justificar, para o leitor, o ponto de vista escolhido. (INEP, 2018, p. 19)

Dessa forma, fica evidente que, ao falar de autoria, o foco maior não é na originalidade da análise acerca de um assunto, mas essencialmente em como o estudante se articula para defender o seu ponto de vista. Por isso, percebemos uma relação entre o que se espera da competência 3 segundo a matriz do Enem e as discussóes de Possenti (2002) na seção anterior.

É necessário lembrar que tomar o texto como unidade é perceber que "um conjunto de contextos e de conhecimentos (linguísticos, cognitivos, interacionais) está envolvido no processo da (re)construção dos sentidos que se empreende durante a compreensão e a produçáo de um texto." (CAVALCANTE, $2017,28)$. Assim, o estudante precisa desenvolver estratégias que orientem a leitura do avaliador de modo que esse confira sentido ao texto a partir de tais diretrizes, ou seja, a coerência.

\subsection{SOBRE A COERÊNCIA}

É necessário entendermos melhor o conceito de coerência e os critérios para desenvolvê-la não apenas por essa categoria estar presente na cartilha do participante, mas por acreditarmos que essa compreensão é realmente necessária para a construção da autoria em textos de alunos candidatos ao Enem - uma maioria de estudantes nos anos finais do ensino médio.

Segundo Koch e Travaglia, a coerência

está diretamente ligada à possibilidade de se estabelecer um sentido para o texto, ou seja, ela é o que faz com que o texto faça sentido para os usuários, devendo, portanto, ser entendida com o um princípio de interpretabilidade, ligada à inteligibilidade do texto numa situação de comunicação [...] (KOCH, TRAVAGLIA, 2015, p. 21). 
Nota-se, portanto, que essa categoria está associada à relação entre a forma como o autor constrói o seu texto de forma a orientar o modo como o leitor interpretará o que foi produzido. A coerência irá possibilitar caminhos para leituras do texto a partir dos sentidos estabelecidos.

Para Cavalcante (2017), a coerência está associada à capacidade de se fazer entender em um texto e, para isso, "a noção de coerência engloba não apenas a unidade semântica, mas também, e especialmente, todas as inferências que precisam ser feitas para que os sentidos sejam construídos." (2017, p. 31-32). Ainda conforme a autora, as inferências são produzidas a partir dos processos cognitivos que associam diversos sistemas de conhecimento do leitor quem constrói o sentido no texto lido a partir da materialidade linguística.

Dentro do universo profissional do professor de língua portuguesa, especialmente no componente curricular de redação, a orientação acerca do desenvolvimento da coerência textual é um desafio, mas tem como amparo as metarregras de Charolles (1988) para identificar as chamadas quebras localizadas na coerência.

Essas metarregras foram disseminadas no Brasil por Costa Val (1999), sendo elas: continuidade (retomadas de elementos), progressão (adição de informações novas), não contradição (não se contradizer nem no mundo externo ao texto, muito menos interno) e articulaçáo (forma de encadeamento dos fatos e conceitos apresentados).

De fato, a existência de textos incoerentes é uma questão que divide a opinião de linguistas, isto é, alguns consideram que existem textos sem qualquer sentido enquanto outros concebem como impossível a existência de textos sem sentido algum, ou seja, todos os textos teriam algo de aceitável. Para Charolles (1988), a incoerência só existiria em textos que não atendessem à situação de comunicação. Concordamos com a ideia de que, embora haja produções textuais com diversas quebras de coerência, não podemos encará-las como completamente incoerentes, mas com partes problemáticas.

A coerência precisa ser vista pelo público das escolas como uma estratégia que depende do domínio do texto por parte de quem escreve. Essas metarregras mencionadas são importantes também por tornarem mais concreto o modo como usar essas estratégias para que o aluno crie um texto coerente e argumentativo.

$\mathrm{Na}$ cartilha do participante, observamos a presença de orientaçóes para a produção de um texto coerente, a partir de um projeto de texto. É colocado que no projeto de texto: "são definidos quais argumentos serão mobilizados para a defesa de sua tese, quais os momentos de introduzi-los e qual a melhor ordem para apresentá-los, de modo a garantir que o texto final seja articulado, claro e coerente.” (INEP, 2018, p. 18). Percebemos, assim, a importância da coerência para a construção da autoria, mas, principalmente, a necessidade de fomentar no aluno o bom desenvolvimento dessa categoria a fim que o estudante alcance seus objetivos.

\section{PROPOSTAS DE ATIVIDADES}


As propostas de atividades criadas por nós são voltadas para estudantes do ensino médio porque desejamos que eles desenvolvam autoria a partir do que a matriz de referência do ENEM espera para um texto de excelência. Para a elaboraçáo delas, primeiro, buscamos textos que pudessem conversar com a realidade dos alunos, mas, principalmente, que fossem textos de opiniáo, pois produzimos as perguntas pensando nos critérios exigidos pela cartilha do participante, como necessário para o desenvolvimento da autoria, isto é, projeto de texto, estratégias argumentativas e coerência.

\subsection{ATIVIDADE 1}

Objetivo: perceber no texto estratégias argumentativas que marquem a autoria.

Descriçáo da atividade: a atividade a seguir é composta por um texto sobre as redes sociais e como o seu uso incorreto pode gerar efeitos negativos na vida de jovens. Foram feitas quatro questóes para que os estudantes as respondam com o objetivo que eles entendam as estratégias usadas pela autora do texto e com que objetivo ela as utilizou.

Leia o texto a seguir e responda ao que se pede.

\section{Redes sociais: quando compartilhar é humilhar}

(Rosario G. Gómez)

O youtuber que há dois anos deu um biscoito recheado de pasta de dente a um mendigo em Barcelona, gravou a cena e a publicou na Internet saberia que estava cometendo um crime contra a integridade moral se tivesse intuído que o mundo virtual é regido pelos mesmos direitos e obrigaçóes que o entorno físico. Humilhou uma pessoa vulnerável. E para agravar a situação o divulgou maciçamente através de seu próprio canal do YouTube. Há duas semanas, foi condenado a 15 meses de prisão. As redes sociais não são uma simples e inocente conversa de bar. Têm um eco infinito e, frequentemente, distorcem e corroem a convivência.

O desconhecimento por parte dos usuários é monumental. "Temos um problema de pedagogia e educação das redes", como diz o coordenador do curso de pós-graduação de Marketing Digital de La Salle, Ricard Castellet. "Estamos diante de uma revolução da comunicação. Uma mudança radical. Em 10 anos usos e costumes se modificaram. A sociedade está aprendendo a utilizar essas plataformas e deveria existir formação obrigatória no colégio para ensinar as possibilidades negativas das redes e seus perigos. É preciso educar na escola e na família para que o uso seja coerente e racional”.

Utilizar incorretamente essas plataformas é nocivo à convivência. De modo que ganhou importância uma corrente de opinião que pede maior regulamentação da Internet e das redes sociais. "Se esses canais são utilizados para destruir a reputação de uma pessoa, é preciso ter normas”, diz Castellet. Para evitar situaçóes dramáticas, não são poucos os que pretendem ativar no ecossistema de trabalhos manuais de boas práticas. Essas barreiras contra incêndios seriam, de acordo com Raquel Herrera, uma garantia dos direitos e deveres das empresas para proteger a reputação de seus funcionários.

As mudanças tecnológicas avançam a um ritmo vertiginoso e a sociedade náo os assimila com a 
mesma celeridade. Gómez Quijano utiliza uma metáfora: "As pessoas não são capacitadas para dirigir uma Ferrari, e isso gera problema importantes". As redes sociais são uma ferramenta muito poderosa para que os usuários não tenham formação. "Isso está explodindo em nossas mãos e vamos aprendendo por tentativa e erro", acrescenta.

É justamente essa falta de formação e aprendizagem no uso das redes que torna os usuários altamente manipuláveis. Para mitigar esse poder onímodo, o Conselho da Europa dá uma receita: estabelecer fórmulas de cooperação entre as redes sociais e as autoridades públicas como antídoto aos venenos do ciberespaço: a intolerância, a desinformação, a incitação ao ódio, os ataques à privacidade.

Disponível em: https://brasil.elpais.com/brasil/2019/06/14/cultura/1560533971_274766.html Acesso em: 01.07.2019. Texto adaptado.

Questáo 1 - No primeiro parágrafo, o autor inicia criticando o caso de um youtuber que ofereceu um biscoito recheado com pasta de dente a um mendigo. Com base nessa informação, responda:

Item A: Que termos, expressóes ou trechos o autor utiliza para marcar que o comportamento do rapaz foi inadequado?

Comentário: iniciamos as questôes a partir de interpretação textual da introdução para que o estudante perceba que a autora começa o texto apresentando um exemplo específico, relacionado à percepçáo dela sobre o crime do youtuber, para chegar à discussão geral acerca dos usos das redes sociais. Essa primeira pergunta, embora mais direcionada à interpretação de texto, deixa evidente a progressão textual, conforme as metarregras mencionadas por Cavalcante (2017), gerada pela autora (do texto da atividade) ao trazer informaçôes novas.

Item B: Para o autor do texto, o youtuber sabia que estava cometendo um crime? Justifique sua resposta com um trecho do texto:

Comentário: esse item é colocado para que o estudante note como as escolhas lexicais tornam claros, ou não, os objetivos de quem escreve a partir de uma articulação textual, enquanto metarregra, bem elaborada.

Item C: Para confirmar o seu argumento de que o desconhecimento sobre direitos e obrigaçóes nas redes existem, o autor utiliza a fala de um coordenador do curso de pós-graduação em Marketing Digital, Ricard Castellet. Por que essa estratégia foi usada?

Item D: Por que Castellet considera as normas necessárias?

Comentário: os itens C e D são postos para que seja percebido como o uso de argumentos de autoridade contribuem para o desenvolvimento textual. Essa estratégia vai ao encontro do que Possenti (2002, p. 112 e 113) discute sobre indícios de autoria com a categoria "dar voz a outros enunciadores", pois é necessário trazer outros pontos de pontos de vista de outros enunciadores especialistas no assunto em que está sendo tratado para gerar uma reflexão e trazer o ponto de vista do enunciador do texto.

\begin{tabular}{c|c|c|c}
\hline Revista Linguagem em Foco & Fortaleza, CE & v. 12 n. 1 & ISSN 2674-8266 \\
\hline
\end{tabular}


Questáo 2 - Qual a relação entre a fala de Gomes Quijano e a atitude do youtuber?

Comentário: com essa questão, espera-se do estudante a percepção de que o uso de comparaçóes contribui para a argumentação no texto.

Questáo 3 - No último parágrafo, Rosario Gomez conclui o texto com uma informação nova, qual? Explique por que a autora traz essa informação na conclusão.

Comentário: A informação nova é a de que a falta de formação e de domínio no uso das redes torna os usuários altamente manipuláveis. Após a argumentação acerca da falta de formação, a autora mostra uma consequência para isso. Tal estratégia argumentativa demonstra a progressão "a partir da adesão de novos conceitos e informações responsáveis pela continuidade.” (CAVALCANTE, 2017, p.34).

Questáo 4 - Considerando o texto lido, você acredita ser necessária uma educação para o uso das tecnologias principalmente na escola? Por quê? Produza, no mínimo, 10 linhas para a sua explicação.

Comentário: A culminância dessa atividade se daria com a produçáo de um pequeno texto relacionado ao assunto, mas principalmente relacionado à vida do estudante, por isso a sugestão de fazê-lo refletir acerca do uso das tecnologias no ambiente escolar. Para a construção do texto, é importante que o professor mostre, ao responder as atividades, como as estratégias argumentativas ficam evidentes no texto, existiu uma organização anterior para que o texto gerasse convencimento. De forma semelhante, espera-se que o estudante produza um texto consciente do uso de estratégias argumentativas o que vai ao encontro do que Orlandi (1988, p. 69) defende: o efeito-sujeito. Este "coloca o sujeito como origem de seu dizer e representa o sentido como transparente".

Comentário geral sobre a atividade: Nesta atividade, desejamos que o estudante leia o texto e, ao responder às questóes, perceba que o projeto de texto é fundamental para que a produção seja coerente e consequentemente passe segurança ao leitor; também gostaríamos que o estudante notasse como o uso de argumentos de autoridade são importantes. Esses objetivos corroboram o que Cavalcante (2017, p. 31 e 32) defende, ou seja, "a noção de coerência engloba não apenas a unidade semântica, mas também, e especialmente, todas as inferências que precisam ser feitas para que os sentidos sejam construídos" além de "dar voz a outros enunciadores" como afirma Possenti (2002, p. 112 e 113) com os argumentos de autoridade.

\subsection{ATIVIDADE 2}

Objetivo: Analisar como a colunista Eliane Brum estabelece o seu projeto de texto.

Descriçáo da atividade: nesta atividade, retornamos com um texto náo-literário que fala sobre a importância da atuação das crianças e dos jovens no mundo. Nas questôes, buscamos fazer perguntas que tornassem possível a análise de como são usadas as estratégias argumentativas e como elas influenciam no 
projeto de texto.

Leia o texto a seguir e responda as atividades:

\section{As crianças tomam conta do mundo}

(Eliane Brum)

A luta contra o aquecimento global é hoje liderada por garotas de vários países do mundo. Estudantes secundaristas, a maioria. Mulheres muito jovens, carregando um novo espírito do tempo no mundo sem tempo, em que só há 12 anos para tentar impedir que o planeta aqueça mais do que 1,5 graus Celsius e o futuro logo ali seja uma vida muito ruim para todos, impossível para os mais pobres e os mais frágeis. Jovens mulheres com muito pânico porque os pais e avós ferraram o planeta em que vão viver e se comportam como gente mimada e egoísta que faz apenas o que quer sem se preocupar com as consequências nem mesmo para seus próprios filhos e netos. Uma parcela da espécie humana chegou a um nível de individualismo que nem mesmo protege a prole naquilo que é fundamental - e o presente se torna absoluto. De repente os mais jovens perceberam que a sobrevivência está comprovadamente ameaçada e os governantes estão brincando no Twitter. [...]

A novíssima geração de humanos teve a extrema má sorte de nascer num momento histórico em que os pais náo conseguem lidar com a questáo do tempo. Os adultos atuais cresceram bombardeados pelo imperativo do consumo que prometia prazer imediato, reiniciado a cada ato de compra, num looping infinito. O tempo passou a ser um presente estendido. Tudo o que existe é o agora do qual é preciso arrancar o máximo. É este o mundo em que cidadãos foram convertidos em consumidores. É este o funcionamento dos adultos atuais num momento histórico em que o aquecimento global, comprovadamente causado por ação humana, se não for barrado, mudará a face do planeta. [...]

Nunca houve nada parecido na história. Em nenhuma história. Os filhotes tentam salvar o mundo que os espécimes adultos destroem sistematicamente. Para além dos efeitos concretos sobre o futuro da humanidade, serão necessários muitos anos de estudos para compreender os efeitos desta inversão sobre a forma de compreender o mundo e seu lugar no mundo daqueles que serão adultos amanhã. Mas, para isso, é preciso antes ter amanhã.

Disponível em: https://brasil.elpais.com/brasil/2019/02/27/opinion/1551290093_277722.html. Texto adaptado. Acesso em 13.08.2019.

Questáo 1: O texto de Eliane Brum circula na coluna “Opinião” do jornal El País. Por estar nesse espaço de informação, nota-se que a autora assume um posicionamento acerca do descuido dos adultos para com a natureza. Que posicionamento é esse?

Comentário: Por ser a primeira questão, esperamos que o estudante se atenha inicialmente a apenas entender o posicionamento da autora já que o texto é argumentativo.

Questáo 2: No primeiro parágrafo do texto, a colunista afirma que: "os pais e avós ferraram o planeta em que vão viver e se comportam como gente mimada e egoísta que faz apenas o que quer sem se preocupar com as consequências nem mesmo para seus próprios filhos e netos.” No texto, como Eliane Brum

\begin{tabular}{c|c|c|c}
\hline Revista Linguagem em Foco & Fortaleza, CE & v. 12 n. 1 & ISSN 2674-8266 \\
\hline
\end{tabular}


explica histórica e culturalmente a razão de adultos hoje agirem dessa forma?

Comentário: Espera-se que nessa questão o estudante compreenda que o segundo parágrafo do texto se destina a explicar o motivo de os adultos agirem de forma táo destrutiva: o "imperativo do consumismo", demonstrando a realizaçáo de um ponto de vista por parte do autor, conforme coloca Bakhtin (2010).

Questáo 3: A fim de fortalecer seu argumento, Eliane Brum faz uma comparação das crianças e adolescentes com prole e filhotes (linhas 11 e 25, respectivamente), termos geralmente associados aos animais. $\mathrm{O}$ que essa comparação sugere?

Comentário: Nessa questão, esperamos que seja perceptível como o humano parece ter perdido um instinto natural, o de cuidar da prole, apenas para satisfazer suas necessidades imediatas.

Comentário geral sobre a atividade: Nesta atividade, buscamos trazer mais uma possibilidade de se trabalhar a construção da autoria (Possenti, 2013) em textos de opinião mostrando que existem estratégias argumentativas a partir de quem escreve, contribuindo assim para o reconhecimento pelos estudantes de que é necessário desenvolver um projeto de texto antes e durante o processo de escrita.

As atividades propostas nesta seção tiveram como objetivo contribuir para o ensino de produção textual, especificamente no quesito desenvolvimento da autoria do aluno, particularmente com o uso de estratégias argumentativas, projeto de texto e coerência.

Esses elementos são importantes principalmente para alunos de pré-vestibular, por estarem alinhados ao que a cartilha do estudante propóe como essencial para que o estudante atinja nota máxima. Todavia, é importante salientar que as atividades não são destinadas apenas a este grupo. Além disso, sabe-se que são trabalhados outros gêneros argumentativos nas escolas que também precisam de uma organização para serem produzidos.

Embora as atividades estejam mais direcionadas ao aspecto de perguntas e respostas e não seja solicitado que os alunos produzam algum texto, nossa proposta foi de fazê-los primeiro compreender como outros escritores deixam evidente o seu projeto de texto em seus textos.

Além do projeto de texto perceptível nos dois textos de apoio usados nessas atividades, nota-se que os argumentos utilizados são perpassados por outros discursos, assim como Orlandi (1988) considera necessário que o seja.

\section{CONSIDERAÇÓES FINAIS}

Ao refletirmos sobre o Enem exigir marcas de autoria nos textos de participantes concludentes do ensino médio, nosso trabalho buscou contribuir, através de uma discussão acerca da autoria (POSSENTI, 2013) das atividades, para a análise de como o Enem compreende tal conceito e como o aluno pode aprender a desenvolvê-la em seus textos através de propostas de atividades. Vimos que essa temática é ampla, havendo várias pesquisas sobre o assunto, mas, apesar de tal amplitude, o debate não se esgota.

A discussão teórica sobre autoria e sobre coerência (CAVALCANTE, 2017) viabilizou o nosso 
objetivo geral de criar novas atividades de ensino aos docentes, principalmente, do segmento do ensino médio. Essas atividades foram criadas com a finalidade de facilitar o trabalho docente, com textos sobre tecnologia e protagonismo infanto-juvenil: "Redes sociais: quando compartilhar é humilhar", cujo assunto está presente na realidade do adolescente, visto que este público está cada vez mais conectado às redes virtuais, e "As crianças tomam conta do mundo", o qual traz uma temática atual e pertinente: $\mathrm{o}$ homem e sua exploração desenfreada do meio ambiente.

Como foi dito, buscamos trazer textos que motivassem a leitura - devido às temáticas e à linguagem mais acessível - e fizessem os alunos identificar nas produções a importância da organização textual, dos argumentos consistentes e da escolha vocabular dos autores. Como vimos, durante essa pesquisa, a autoria se destaca quando o candidato constrói um texto coerente e com bons argumentos, inclusive segundo a cartilha do participante.

Observamos como as teorias sobre autoria estão bastante vinculadas à questão literária, principalmente com Barthes (2012), Foucault (2009) e Bakhtin (2010). Consideramos ainda que é possível trazer essas reflexóes para o âmbito escolar e refletir sobre a produção desses alunos enquanto um texto que contém aspectos autorais ou sobre o modo como esse estudante elabora sua redaçáo constitui autoria.

Por fim, desejamos que esta pesquisa contribua para os estudos sobre a temática, mas, principalmente, que as atividades sejam aplicadas em sala de aula como forma de os alunos terem a experiência da leitura dos textos, de responder conscientemente as questóes colocadas para compreender como é importante estabelecer um projeto de texto. Assim, será possível avaliar se os exercícios realmente podem contribuir para o desenvolvimento da autoria por estudantes do ensino médio.

\section{REFERÊNCIAS}

BAKHTIN, M. O plurilinguismo no romance. In: Questóes de literatura e de estética. 6. ed. São Paulo: Hucitec Editora, 2010.

BARTHES, R. A morte do autor. In: O rumor da língua. 3 ed. Tradução. Mário Laranjeira. São Paulo: Editora WMF Martins Fontes, 2012.

CAVALCANTE, M. M. Os sentidos do texto. São Paulo: Contexto, 2017.

CAVAlHEIRO, J. dos S. A concepção de autor em Bakhtin, Barthes e Foucault. Signum: Estud. Ling., Londrina, n. 11/2, p. 67-81; dez. 2008.

CHAROLLES, M. Introdução aos problemas da coerência dos textos. Trad. Paulo Otoni. In: GALVES, C; ORLANDI, E. P.; OTONI, P. (Orgs.). O texto: escrita e leitura. Campinas: Pontes, 1988, p. 39 - 85.

COSTA VAL, M. G. Redaçáo e textualidade. São Paulo: Martins Fontes, 1999.

FARACO, C. A. Autor e autoria. In: BRAIT, B. (Org.). Bakhtin: conceitos-chave. 5. ed. São Paulo: Contexto, 2014. p.37-60.

\begin{tabular}{l|l|l|l}
\hline Revista Linguagem em Foco & Fortaleza, CE & v. 12 n. 1 & ISSN 2674-8266 \\
\hline
\end{tabular}


FOUCAULT, M. Ditos e Escritos: Estética - literatura e pintura, música e cinema (vol. III). 2 ed. Rio de Janeiro: Forense Universitária, 2009. p. 264-298.

INSTITUTO Nacional de Educação e Pesquisa. Redação no Enem 2018 - Cartilha do Participante. Brasília, 2018.

Enem. Disponível em: < http://portal.inep.gov.br/web/guest/enem >. Acesso em 15 jul. 2019.

KOCH, I. V. e TRAVAGLIA, L. C. A coerência textual. São Paulo: Contexto, 2015.

ORLANDI, E. P. Unidade e dispersão: uma questão do texto e do sujeito. In: Discurso e leitura. - São Paulo: Cortez; Campinas, SP: Editora da Universidade Estadual de Campinas, 1988.

PADILHA, S. Relendo Bakhtin: autoria, escrita e discursividade. Polifonia, Cuiabá. v.18, n.23, p.91102, jan./jun., 2011.

POSSENTI, S. Indícios de autoria. Perspectiva, v. 20. n. 1, p. 105-124, jan./jun. 2002.

Notas sobre a questão de autoria. Matraga, Rio de Janeiro, v. 20, n. 32, jan./jun. 2013.

VOLÓCHINOV, V. Marxismo e filosofia da linguagem: problemas fundamentais do método sociológico na ciência da linguagem. Tradução: Grillo, Sheila; Américo, Ekaterina Vólkova. Grillo, Sheila. Sáo Paulo: Editora 34, 2017. 